\title{
Effect of Annealing on Hardness and the Modulus of Elasticity in Bulk Nanocrystalline Nickel
}

\begin{abstract}
ANNA TORRENTS, HEATHER YANG, and FARGHALLI A. MOHAMED
Experiments on hardness and the modulus of elasticity were conducted at room temperature on samples of electrodeposited (ED) nanocrystalline (nc) Ni that were annealed at temperatures ranging from 323 to $693 \mathrm{~K}\left(50\right.$ to $\left.420^{\circ} \mathrm{C}\right)$. The results showed the presence of three regions: I, II, and III. In region I $\left(300 \mathrm{~K}\left(27^{\circ} \mathrm{C}\right)<T<350 \mathrm{~K}\left(77^{\circ} \mathrm{C}\right)\right)$, the hardness and the elastic modulus remained essentially constant. In region II $\left(350 \mathrm{~K}\left(77^{\circ} \mathrm{C}\right)<T<500 \mathrm{~K}\left(227^{\circ} \mathrm{C}\right)\right.$ ), both the hardness and the elastic modulus increased. In region III $\left(T>500 \mathrm{~K}\left(227^{\circ} \mathrm{C}\right)\right)$, the hardness dropped and then decreased with increasing grain size, whereas the modulus of elasticity approached a maximum plateau of $\sim 240 \mathrm{GPa}$. It is suggested that while the increase in hardness in region II can be attributed in part to the formation of annealing twins, which serve as a source of strengthening, the decrease in hardness above $500 \mathrm{~K}\left(227^{\circ} \mathrm{C}\right)$ is due to the occurrence of significant grain growth. The increase in the modulus of elasticity with increasing temperature in region II was attributed to the preferred orientation along (200) that was observed in the as-received samples and that continuously diminished with increasing temperature. In region III $\left(T>500 \mathrm{~K}\left(227^{\circ} \mathrm{C}\right)\right)$, the preferred orientation disappeared and, a result, the modulus of elasticity approached a constant value of approximately $240 \mathrm{GPa}$.
\end{abstract}

DOI: $10.1007 /$ s11661-009-0147-0

(C) The Author(s) 2010. This article is published with open access at Springerlink.com

\section{INTRODUCTION}

NANOCRYSTALLiNE (nc) materials are defined as single- or multiphase polycrystals that are characterized by grain sizes in the range 1 to $100 \mathrm{~nm}$. Because of their small grain size, grain boundaries, junction lines, and nodes have significant volume fractions that influence properties far more strongly than in more conventional microstructures.

The mechanical properties of nc materials have been the subject of a number of studies. ${ }^{[1,2]}$ In general, these studies have been motivated in part by a growing interest in assessing the potential of nc materials as materials for engineering applications. Primary among the mechanical properties that have received considerable attention are the hardness and the modulus of elasticity. ${ }^{[3-13]}$

Studies of the hardness in nc materials focused in part on the identification of parameters that might influence hardness in terms of softening or strengthening as a result of annealing. Fougere et al. ${ }^{[11]}$ reported an increased hardness with decreasing grain size for $\mathrm{nc}-\mathrm{Cu}$ and nc-Pd when samples were annealed at 423 and $569 \mathrm{~K}\left(150\right.$ and $\left.296^{\circ} \mathrm{C}\right)\left(\sim 0.315 T_{m}\right.$, where $T_{m}$ is the melting point), respectively. Such strengthening was explained in terms of the reduction of porosity during annealing. Chen et al. ${ }^{[12]}$ studied Ni-P hardness behav-

ANNA TORRENTS and HEATHER YANG, Graduate Research Assistants, and FARGHALLI A. MOHAMED, Professor, are with the Department of Chemical Engineering and Materials Science, University of California-Irvine (UCI), Irvine, CA. Contact e-mail: famohame@uci.edu

Manuscript submitted March 18, 2009.

Article published online January 28, 2010 ior after heat treatment in the temperature range 623 to $873 \mathrm{~K}$ (350 to $\left.600{ }^{\circ} \mathrm{C}\right)$. Their results ${ }^{[12]}$ indicated that hardening occurred below a critical temperature, located between 623 and $673 \mathrm{~K}$ ( 350 and $400{ }^{\circ} \mathrm{C}$ ), followed by softening after annealing at higher temperatures. Chen et al. ${ }^{[12]}$ associated the increase in hardness with an increasing annealing temperature with the formation of nanocrystals. Yang and Vehoff ${ }^{[13]}$ annealed nc-Ni samples at 573 and $673 \mathrm{~K}\left(300\right.$ and $400{ }^{\circ} \mathrm{C}$ ) for different holding times to produce grain sizes in the range $30 \mu \mathrm{m}$ to $30 \mathrm{~nm}$. They reported ${ }^{[13]}$ that the hardness increased with decreasing grain size and that the hardness scaled with the dislocation density within the grains.

Early studies on the moduli of elasticity in nc materials were carried out using materials prepared by the gas condensation method. These studies revealed that the values of the modulus of elasticity for nc materials were significantly lower than for coarsegrained counterparts. ${ }^{[14,15]}$ The lower values of the moduli of elasticity in nc materials prepared by the gas condensation method were explained in terms of the presence of porosity. ${ }^{[15,16]}$

In the present study, the variations in hardness and in the modulus of elasticity in $\mathrm{nc}-\mathrm{Ni}$ prepared by the electrodeposition technique as a function of the annealing temperature were studied. The investigation was motivated by two primary considerations. First, no detailed investigation has yet been carried out to provide results on the variation in the hardness of nc-Ni as a function of the annealing temperature over a wide range of temperatures. Second, data reported for porosity-free nc materials have indicated that the values of their moduli of elasticity are comparable to those of coarse-grained counterparts. However, it was reported 
that nc-Ni produced by electrodeposition exhibited a preferred texture. ${ }^{[17]}$ At present, there is no information about the effect of the presence of the preferred texture in electrodeposited (ED) nc-Ni on the modulus of elasticity.

\section{EXPERIMENTAL PROCEDURE}

\section{A. Material}

The ED nc-Ni was used in the present investigation. The material, which was used in two previous investigations, ${ }^{[17,18]}$ was provided by Integran Technologies Inc. (Toronto, ON, Canada) in the form of $0.5-\mathrm{mm}$ sheets with initial grain sizes of 20 and $100 \mathrm{~nm}$. The ED nc-Ni was chosen for two primary reasons. First, according to the available information, ${ }^{[19]}$ the electrodeposition route can produce a fully dense nc-Ni with a fairly grain-sized distribution. Second, the results of an earlier investigation in which thin foils from the cross section of (ED) nc-Ni showed the absence of columnar structures. ${ }^{[18]}$ The chemical composition of as-received (ED) nc-Ni is given in Table I. An examination of the chemical analysis as provided by this table shows the presence of $\mathrm{S}$ and $\mathrm{C}$ impurities. The concentration of impurities is less than $0.1 \mathrm{wt}$ pct and can be considered as interstitial-type impurities. The presence of these impurities has been attributed to the use of additives such as coumarin and saccharin in the electrolyte bath.

\section{B. Characterization}

As-received (ED) nc-Ni samples with an average grain size of $20 \mathrm{~nm}$ were annealed at nine different temperatures ranging from 323 to $693 \mathrm{~K}\left(50\right.$ and $\left.420{ }^{\circ} \mathrm{C}\right)$ and two different annealing times, 1 and 25 hours. For each annealing temperature, four specimens were used. After annealing, the samples were rapidly cooled in air. As-received nc-Ni (20 and $100 \mathrm{~nm}$ ) and postannealed samples were characterized using X-ray diffraction (XRD) and transmission electron microscopy (TEM). The TEM was used for the dual purpose of checking the data on grain size that were obtained from XRD and providing information on grain size distribution. In addition, electron backscattered diffraction (EBSD) was used to obtain grain orientation maps.

Grain size measurements were conducted using XRD. A Siemens D5000 diffractometer equipped with a graphite monochromator using copper $K_{\alpha} \quad(\lambda=$ $0.15406 \mathrm{~nm}$ ) radiations was used. General scans with a step size of 0.02 degree ( $2 \theta$ ) and a step time of 2 seconds were used for grain size determination. The integral breadth (IB) method ${ }^{[20]}$ using five strong fcc Ni peaks $(\{111\},\{200\},\{220\},\{311\}$, and $\{222\})$ was used after subtracting the instrumental broadening and $K_{\alpha 2}$ components.

The grain size and grain size distribution measurements were conducted using a Philips* CM 20 trans-

*PHILIPS is a trademark of Philips Electronic Instruments Corp., Mahwah, NJ.

mission electron microscope at $200 \mathrm{kV}$. Samples were prepared by a combination of mechanical grinding and electrojet polishing. The polishing solution used was of the composition 75 pct $\mathrm{HNO}_{3}$ and 25 pet $\mathrm{CH}_{3} \mathrm{OH}$. A current of $8 \mathrm{~V}$ and $2 \mathrm{~mA}$ was used and the temperature was kept below $243 \mathrm{~K}\left(-30{ }^{\circ} \mathrm{C}\right)$. Additional details about the TEM sample preparation are given elsewhere. ${ }^{[17]}$

Grain orientation maps were obtained using Zeiss Ultra 55 scanning electron microscope with an acceleration voltage of $20 \mathrm{kV}$, in which the HKL Flamenco Channel 5 hardware and software are interfaced. Measurements of orientation maps were performed with a step size of $30 \mathrm{~nm}$. The sample preparation required a mechanical polishing, followed by electropolishing at room temperature with a reading voltage of $8 \mathrm{~V}$. The composition used was a mixture of 20 pct $\mathrm{H}_{2} \mathrm{SO}_{4}$ and 80 pet $\mathrm{CH}_{3} \mathrm{OH}$.

\section{Hardness and Modulus of Elasticity}

All samples were mounted in cold mounts, using a mixer of a Buehler EPO-THIN low-viscosity resin and its hardener $(5: 1)$. Mounts were polished using $\mathrm{SiC}$ papers of different grit sizes, starting with $400,600,800$, and 1200 grits, and an alumina powder $0.05 \mu \mathrm{m}$ was used for final polishing. Once polished, the samples were tested to determine hardness and the modulus of elasticity.

Hardness tests were carried out on a microindenter. In particular, microindentation measurements were carried out at room temperature using a Buehler Microtester 5101 equipped with a square base diamond indenter, well known as a Vickers indenter. A load of $10 \mathrm{~g}$ with a holding time of 20 seconds was applied. As mention earlier, the samples tested were annealed at different temperatures varying from 323 to $693 \mathrm{~K}\left(50\right.$ to $420{ }^{\circ} \mathrm{C}$ ) for 1 and 25 hours.

In addition, a nanoindenter was selectively used on an as-received sample and on samples annealed for 25 hours to do the following: (1) measure the hardness and the modulus of elasticity ${ }^{20]}$ and (2) verify the trends obtained from the microindenter. Nanoindentation measurements were performed using an MTS Nanoindenter-XP pyramidal indenter. The area function for the diamond (the relationship between the projected contact

Table I. Chemical Composition of (ED) nc-Nickel

\begin{tabular}{lcccccccc}
\hline Elements & $\mathrm{C}$ & $\mathrm{Si}$ & $\mathrm{P}$ & $\mathrm{S}$ & $\mathrm{Cu}$ & $\mathrm{Co}$ & $\mathrm{B}$ & $\mathrm{Ni}$ \\
\hline Wt Pct & 0.013 & $<0.001$ & 0.003 & 0.058 & 0.023 & 0.071 & 0.0091 & balance \\
\hline
\end{tabular}


area and contact depth) was calibrated by indentations into pure $\mathrm{Ni}$ from 0.5 to $200 \mathrm{mN}$. Indentations were depth controlled to a $500-\mathrm{nm}$ maximum penetration depth with a constant strain rate of $0.05 \mathrm{~s}^{-1}$. All data were corrected for thermal drift and instrumental compliance in the instrument software and were subsequently analyzed for the determination of the modulus of elasticity $E$ and hardness $H$ using the continuous stiffness method procedure developed by Oliver and Pharr. ${ }^{[20]}$

It is worth mentioning that the reported data on the hardness obtained from both the microindenter and the nanoindenter were the average values of more than ten indents.

\section{EXPERIMENTAL RESULTS}

\section{A. Texture}

Figure 1 provides a representative XRD pattern of asreceived (ED) nc-Ni with an average initial grain size of $20 \mathrm{~nm}$. The XRD profile shows strong orientation in (111) followed by (200). In terms of the relative peak intensity, the (200) planes of the experimental XRD profiles are much stronger, compared with the standard JCPDS pattern (04-0850) $\left(I_{200 / 111}=0.75>I_{200 / 111}=\right.$ 0.46). This observation reveals the presence of strongly preferred texture around (200) planes oriented predominantly in the as-received (ED) nc-Ni. These results agree with those previously reported on the microstructural characterization of (ED) nc-Ni by Chauhan and Mohamed, ${ }^{[17]}$ although an extra peak in the XRD profile was not found.

The effect of the annealing temperature on the preferred texture in 20-nm nc-Ni after annealing for 1 hour is shown in Figures 2(a) through (d). An examination of the XRD profiles plotted in these figures reveals that the preferred texture in (ED) $\mathrm{nc}-\mathrm{Ni}$ decreases with increasing both the annealing time and temperature, and that above $500 \mathrm{~K}\left(227^{\circ} \mathrm{C}\right)$, the texture finally disappears (Figure $2(\mathrm{~d})$ ); the relative peak

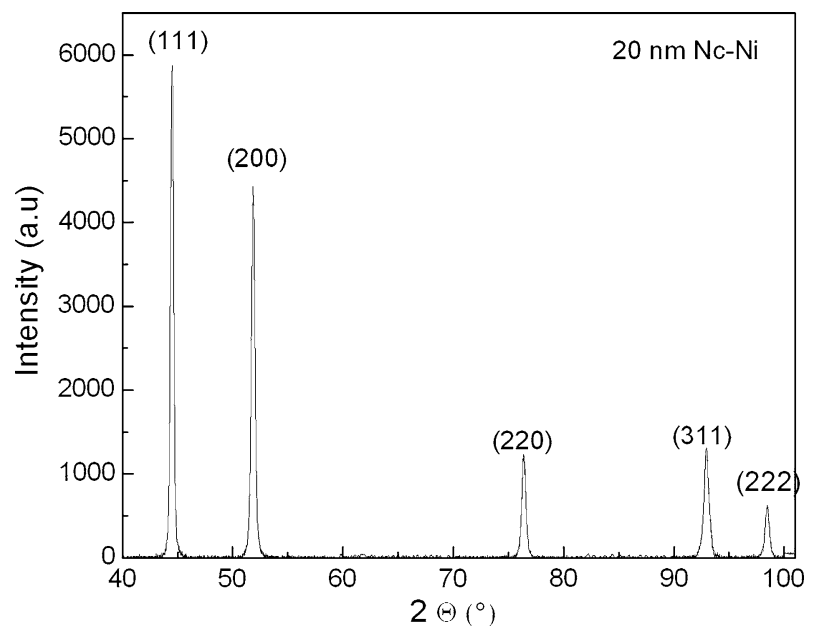

Fig. 1-XRD profile of as-received (ED) nc-Ni with an initial average grain size of $20 \mathrm{~nm}$. intensity decreases from $I_{200 / 111}(\mathrm{a})=0.75$ to $I_{200 / 111}(\mathrm{~d})=$ 0.46 .

\section{B. Grain Size and Grain Size Distribution}

Grain size measurements were performed using the IB method, ${ }^{[21]}$ taking into account five fcc diffraction peaks of $\mathrm{Ni}$, i.e., $(\{111\},\{200\},\{220\},\{311\}$, and $\{222\})$. The average grain sizes for 20- and 100-nm samples prepared from as-received nc-Ni were determined to be $18 \pm 2$ and $96 \pm 9 \mathrm{~nm}$, respectively. The grain size distribution from TEM for 20-nm samples was previously reported. ${ }^{[19]}$ The average grain size obtained from the TEM investigation of the as-received nc-Ni samples agreed well with those estimated from XRD.

The IB method and TEM were also used to calculate the average grain sizes for annealed samples. Histograms of the grain size distribution that were constructed using a number of representative TEM micrographs are shown in Figures 3(a) through (c). In constructing these histograms, approximately 250 grains were used. It was previously reported that the nc-Ni used in the present investigation did not exhibit a columnar structure and that the average grain size in the cross-section view is essentially equal to that in the plane-view section. ${ }^{[19]}$

Table II provides a comparison between the average grain sizes obtained by the IB method and by TEM. According to the data of the table, the measurements using XRD and TEM are in good agreement in respect

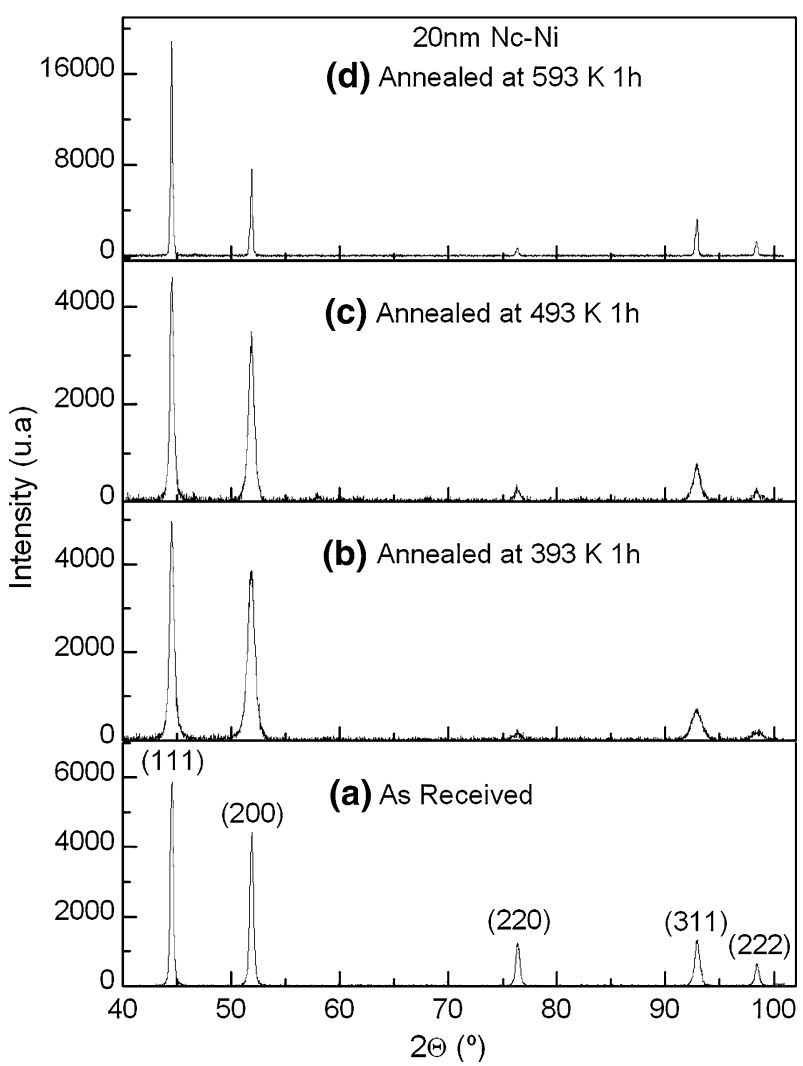

Fig. 2-XRD patterns showing the effect of annealing on 20-nm (ED) nc-Ni. 


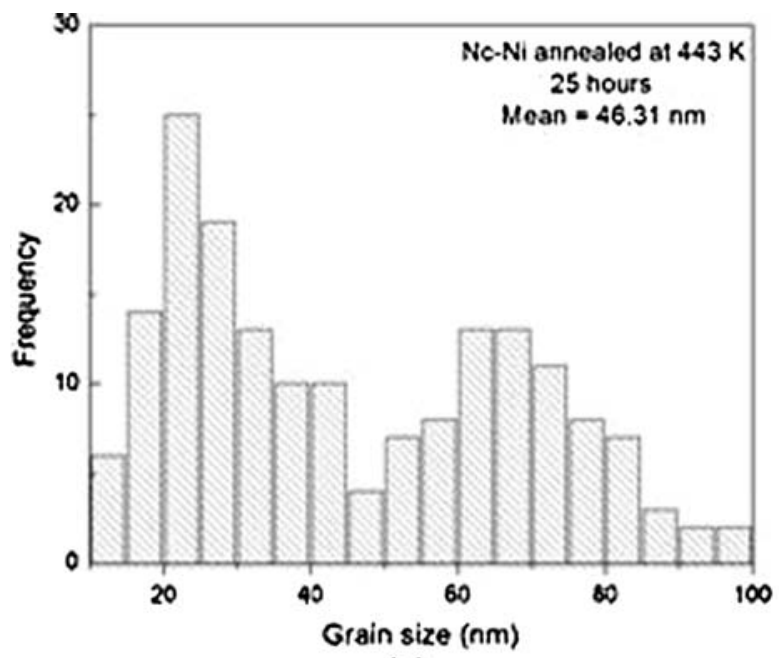

(a)

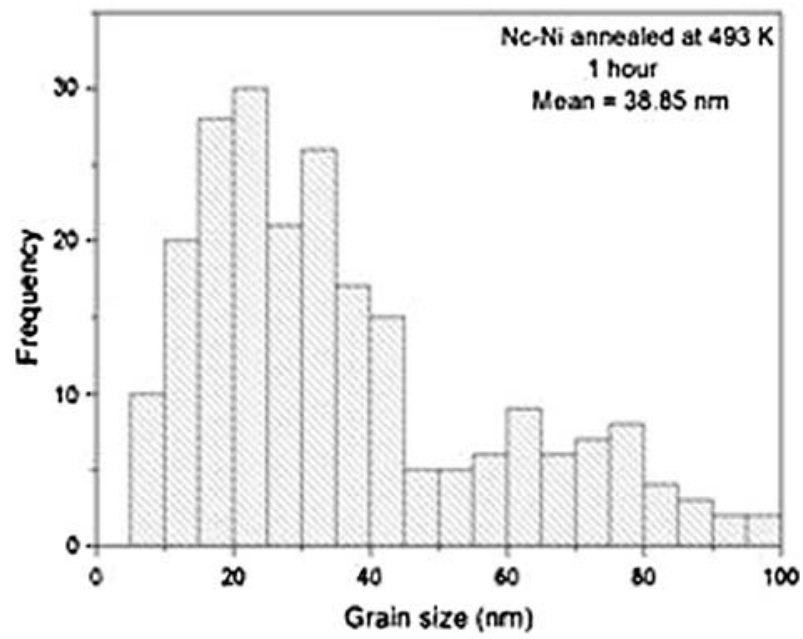

(b)

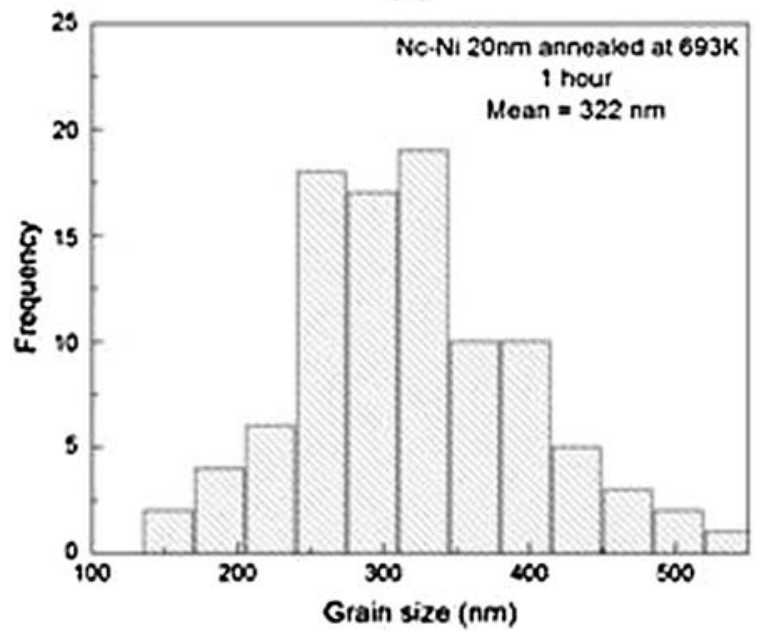

(c)

Fig. 3-TEM grain size distributions in (ED) nc-Ni annealed at $(a)$ $443 \mathrm{~K}\left(170{ }^{\circ} \mathrm{C}\right)$ for $25 \mathrm{~h},(b) 493 \mathrm{~K}\left(220^{\circ} \mathrm{C}\right)$ for $1 \mathrm{~h}$, and $(c) 693 \mathrm{~K}$ $\left(420^{\circ} \mathrm{C}\right)$ for $1 \mathrm{~h}$.

to their calculated average grain sizes for as-received and annealed samples at low temperatures for short times. For post-annealed samples annealed under these conditions (low temperatures and short times), a normal distribution was found to be identical with that previously reported. ${ }^{[17]}$ However, deviations in the values of the average grain sizes were detected when a bimodal grain size distribution with abnormal grain growth was observed. This type of distribution is shown by the histogram of Figure 3(a) and is illustrated by Figures 4(a) and (b), which show TEM micrographs for $20-n m$ nc-Ni samples annealed at $443 \mathrm{~K}\left(170{ }^{\circ} \mathrm{C}\right)$ for 25 hours and $493 \mathrm{~K}\left(220^{\circ} \mathrm{C}\right)$ for 1 hour, respectively. Furthermore, results obtained from XRD analysis were not reliable at temperatures higher than $500 \mathrm{~K}\left(227^{\circ} \mathrm{C}\right)$. In this range of temperature, significant grain growth occurs and the grain size in nc-Ni follows a normal distribution curve, as indicated by the histogram of Figure 3(c). An example for the occurrence of significant grain growth is provided in Figure 4(c), in which a representative TEM micrograph shows the presence of large grain sizes $(>100 \mathrm{~nm})$ in the microstructure of samples annealed at $693 \mathrm{~K}\left(420{ }^{\circ} \mathrm{C}\right)$ for 1 hour.

\section{Hardness}

Hardness data obtained from microindentation using a 10-g load are shown in Figure 5, in which the hardness is plotted $v s$ the inverse square root of the grain size $\left(d^{-1 / 2}\right)$. Included in the figure is a curve that exhibits two branches and that is taken from Reference 22. The first branch (left side) represents conventional Hall-Petch (HP) behavior, ${ }^{[23,24]}$ which signifies that hardness increases with decreasing grain size. The second branch (right side) represents inverse HP behavior, ${ }^{[2]}$ which indicates the opposite trend. An examination of the figure shows two observations. First, the hardness data of the as-received samples, including two additional datum points for $15-$ and $25-\mathrm{nm}$ (ED) nc-Ni, ${ }^{[25]}$ follow the conventional HP equation. Second, the hardness values obtained from microindenter testing using $10 \mathrm{~g}$ agree with the trend and with the magnitude obtained from the nanoindenter.

The data shown in Figure 6 are for 20-nm nc-Ni samples that were annealed for two different holding times, 1 and 25 hours, in the temperature range 323 to $693 \mathrm{~K}\left(50\right.$ to $\left.420{ }^{\circ} \mathrm{C}\right)$. The data are plotted as the hardness against the annealing temperatures. An inspection of the figure reveals the presence of the following three regions, depending on annealing temperatures.

(a) Region I $\left(300 \mathrm{~K}\left(27^{\circ} \mathrm{C}\right)<T<350 \mathrm{~K}\left(77^{\circ} \mathrm{C}\right)\right)$ : in this region, the hardness remains essentially constant and is not affected by an increasing time of annealing.

(b) Region II $\left(350 \mathrm{~K}\left(77^{\circ} \mathrm{C}\right)<T<500 \mathrm{~K}\left(227^{\circ} \mathrm{C}\right)\right)$ : in this region, the temperature region, the hardness slightly increases with increasing grain size and the holding time has no significant effect on the value of hardness.

(c) Region III $\left(T>500 \mathrm{~K}\left(227^{\circ} \mathrm{C}\right)\right)$ : in this region, the hardness drops and then decreases with increasing grain size. In addition, in this region, the hardness depends on the holding time: the higher the holding time, the lower the hardness. 
Table II. Grain Size Values of 20-nm nc-Ni Obtained by XRD and TEM Methods

\begin{tabular}{lrrl}
\hline Sample & XRD $(\mathrm{nm})$ & TEM $(\mathrm{nm})$ & Grain Size Distribution \\
\hline As-received & $18 \pm 2$ & $18.1 \pm 5.36$ & normal, no GG* \\
Annealed at 393 K $\left(120^{\circ} \mathrm{C}\right), 1 \mathrm{~h}$ & $20.5 \pm 2$ & $20.8 \pm 5.03$ & normal, no GG \\
Annealed at $393 \mathrm{~K}\left(120^{\circ} \mathrm{C}\right), 25 \mathrm{~h}$ & $26 \pm 2$ & $31.5 \pm 9.52$ & bimodal, abnormal GG \\
Annealed at $443 \mathrm{~K}\left(170^{\circ} \mathrm{C}\right), 25 \mathrm{~h}$ & $27 \pm 3$ & $46.3 \pm 11.94$ & bimodal, abnormal GG \\
Annealed at $493 \mathrm{~K}\left(20^{\circ} \mathrm{C}\right), 1 \mathrm{~h}$ & $22 \pm 2$ & $38.8 \pm 13.58$ & bimodal, abnormal GG \\
Annealed at $593 \mathrm{~K}\left(320^{\circ} \mathrm{C}\right), 1 \mathrm{~h}$ & $26 \pm 2$ & $240 \pm 73.5$ & normal, GG \\
Annealed at $693 \mathrm{~K}\left(420^{\circ} \mathrm{C}\right), 1 \mathrm{~h}$ & $29 \pm 3$ & $322.3 \pm 40.7$ & normal, GG \\
\hline
\end{tabular}

${ }^{*} \mathrm{GG}=$ grain growth
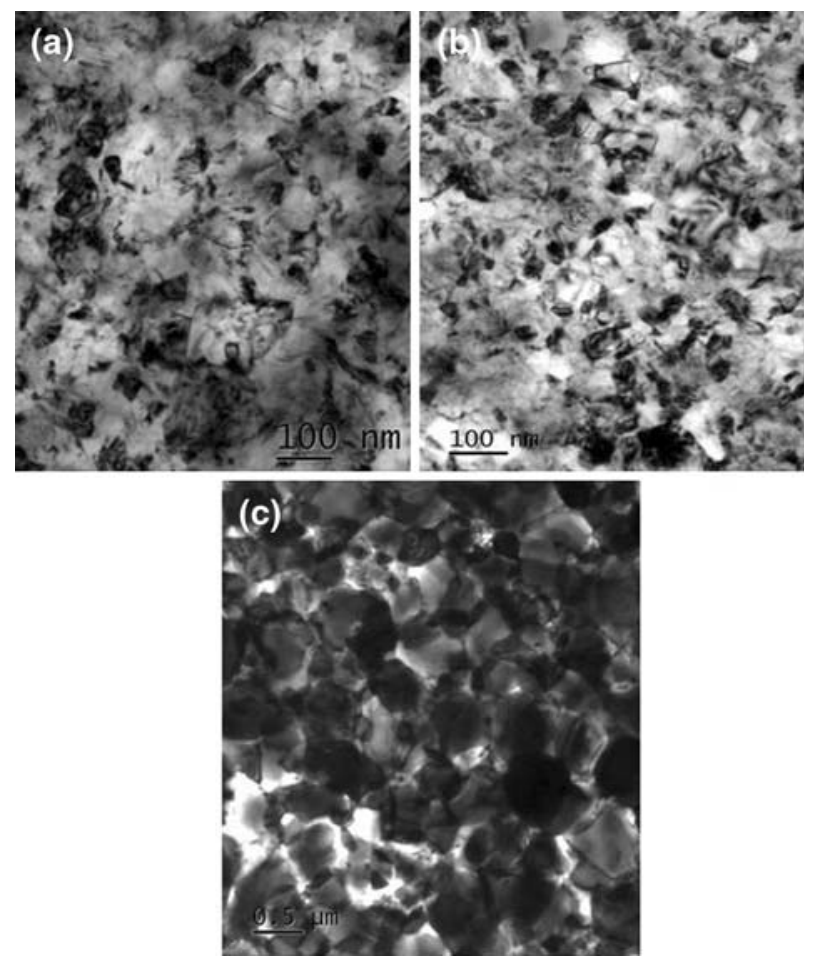

Fig. 4-TEM bright field micrographs of 20-nm (ED) nc-Ni annealed at (a) $443 \mathrm{~K}\left(170{ }^{\circ} \mathrm{C}\right)$ for $25 \mathrm{~h},(b) 493 \mathrm{~K}\left(220^{\circ} \mathrm{C}\right)$ for $1 \mathrm{~h}$, and $(c) 693 \mathrm{~K}\left(420^{\circ} \mathrm{C}\right)$ for $1 \mathrm{~h}$.

\section{Modulus of Elasticity}

Measurements for the modulus of elasticity $E$ of the as-received samples yielded a value of $165 \pm 10 \mathrm{GPa}$. Figure 7 shows the change in the value of the modulus of elasticity for 20-nm samples as a function of the annealing temperature for a holding time of 25 hours. It can be clearly seen that the modulus is constant at the very-low-temperature range (similar in trend to that of region I in Figure 6) but rapidly increases with increasing temperature, approaching a maximum plateau at approximately $240 \mathrm{GPa}$ above $500 \mathrm{~K}\left(227^{\circ} \mathrm{C}\right)$.

\section{DISCUSSION}

\section{A. Microstructure Characterization}

The XRD profile of 20-nm as-received (ED) nc-Ni exhibited strongly preferred texture along the (200) planes (Figure 1). Similar results on (ED) nc-Ni have

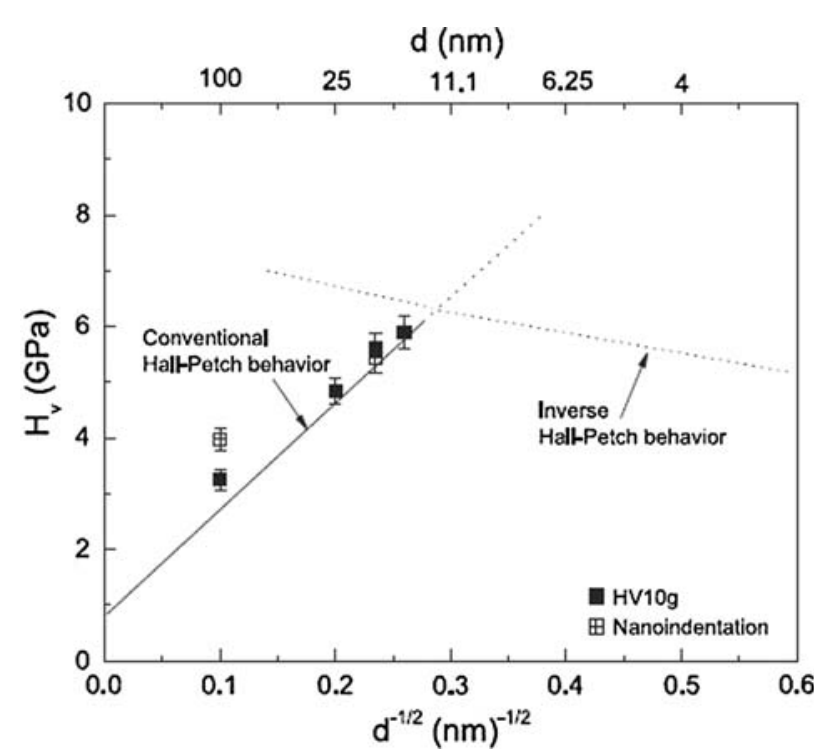

Fig. 5-Hardness of as-received (ED) nc-Ni as a function of the inverse square root of the grain size. Included in the figure is a curve $^{[22]}$ that has two branches representing conventional HP behavior (left side) and inverse HP behavior (right side).

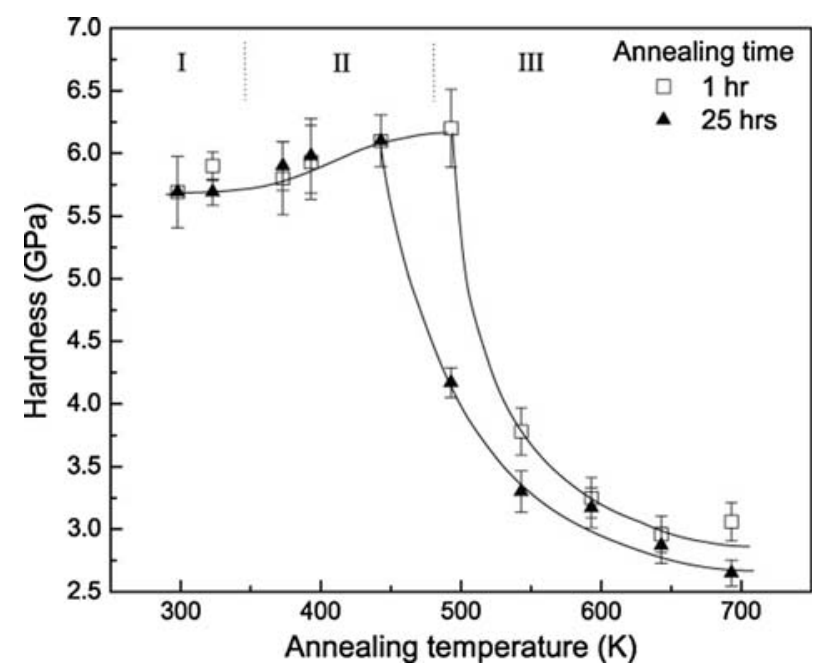

Fig. 6-Microhardness of 20-nm nc-Ni as a function of annealing temperature.

also been reported by several investigators. ${ }^{[17,26-29]}$ This texture was mainly attributed to presence of impurities in the electrolyte bath, namely $\mathrm{S}$ and $\mathrm{C}$, which seem to 
enhance the strength of the (100) texture by reducing the (100) surface energy. The texture was also present in annealed samples (Figure 2). Below $500 \mathrm{~K}\left(227^{\circ} \mathrm{C}\right)$, the preferred orientation along the (200) planes was still present when samples were annealed at 1 and 25 hours, although it diminished with an increasing annealing temperature. Above $500 \mathrm{~K}\left(227^{\circ} \mathrm{C}\right)$, texture was lost and randomly oriented grains were detected, as demonstrated by representative EBSD orientation maps in Figure 8.

The XRD and TEM techniques have been frequently used to compare measurements of grain sizes. The results reported by several investigators ${ }^{[17,30-32]}$ indicated that the measurements obtained from both methods were comparable. However, recent studies ${ }^{[33-35]}$ have demonstrated that grain size measurements from XRD lead to underestimation when deviations in narrow grain size distributions occurred.

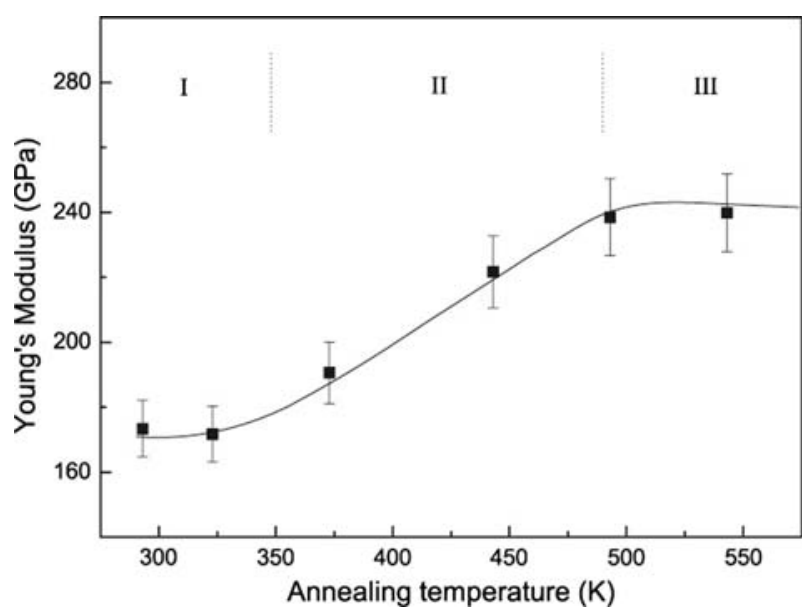

Fig. 7-Young's modulus of $20-\mathrm{nm}$ nc-Ni as a function of annealing temperature.
In the present study, it is shown that the grain size values of as-received (ED) nc-Ni samples measured by XRD and TEM were in excellent agreement, while the values obtained from annealed samples were not (Table II). It is suggested that under this condition, reliable results from XRD are not obtained for the following two reasons: (1) a bimodal distribution of the grain size with a wide grain size distribution exists after annealing at temperatures $<500 \mathrm{~K}\left(227^{\circ} \mathrm{C}\right)$ and (2) significant grain growth occurs after annealing at temperatures $>500 \mathrm{~K}\left(227^{\circ} \mathrm{C}\right)$ and, as a result, the values of grain sizes for a large number of grains in the microstructure exceed the limitation of XRD $(100 \mathrm{~nm})$. Similar observations were made by other investigators ${ }^{[31,33,35]}$ who have reported that XRD is not a valid characterization technique for samples with an inhomogeneous distribution of grain size and for grain sizes $>100 \mathrm{~nm}$.

Grain size measurements inferred from EBSD orientation maps led to average grain sizes that were larger than those obtained using TEM. For example, the average grain sizes in samples annealed at $593 \mathrm{~K}$ $\left(320^{\circ} \mathrm{C}\right)$ for 1 hour and $593 \mathrm{~K}\left(320^{\circ} \mathrm{C}\right)$ for 25 hours were 375 and $453 \mathrm{~nm}$, respectively. This finding is not unexpected, considering the following two factors: (1) EBSD is not an effective procedure for grain sizes $<100 \mathrm{~nm}$ and (2) the grain size measurements via ESBD represent surface measurements.

\section{B. Grain Growth Behavior}

According to the present data, grain growth in (ED) nc-Ni exhibits the following two types of behavior depending on the annealing temperature: (1) below $500 \mathrm{~K}\left(227^{\circ} \mathrm{C}\right)$, anomalous grain growth and bimodal grain size distributions were detected and (2) above $500 \mathrm{~K}\left(227^{\circ} \mathrm{C}\right)$, there was normal grain growth. These types of behavior were noted earlier in bulk nc-Ni by
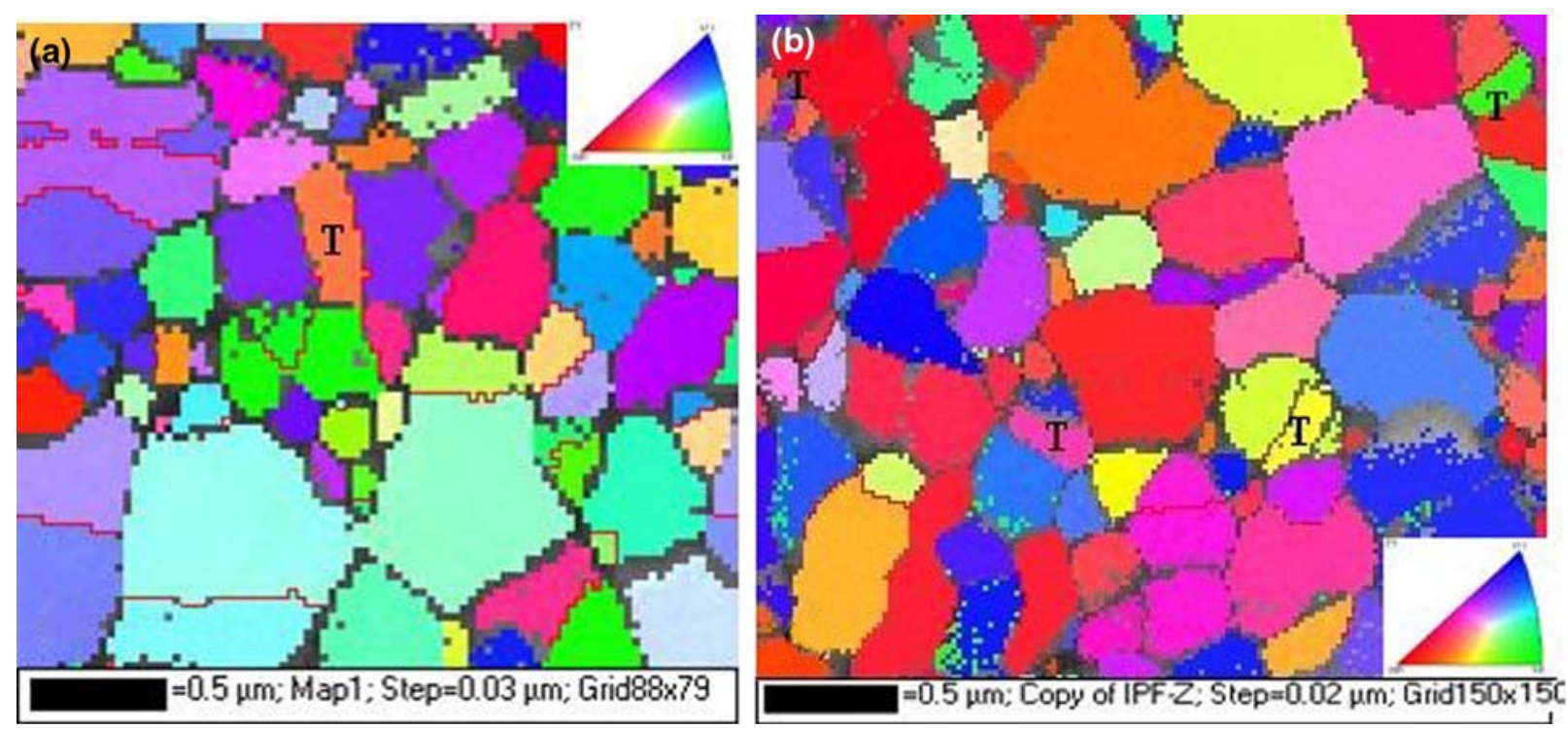

Fig. 8-EBSD orientation map of 20-nm nc-Ni annealed at (a) $593 \mathrm{~K}\left(320{ }^{\circ} \mathrm{C}\right)$ for $1 \mathrm{~h}$ and $(b) 593 \mathrm{~K}\left(320{ }^{\circ} \mathrm{C}\right)$ for $25 \mathrm{~h}$. 
Chauhan and Mohamed, ${ }^{[17]}$ who have characterized each behavior with a different activation energy: a low activation energy of approximately $25 \mathrm{~kJ} / \mathrm{mol}$ below 0.3 $T_{m}$ and a high activation energy of approximately $125 \mathrm{~kJ} / \mathrm{mol}$ above $0.3 T_{m}$. The low activation energy was a characteristic of reordering boundaries for nc metals, while the high activation energy was close to the grain boundary diffusion activation energy value in polycrystalline Ni.

\section{Hardening and Softening}

The present results reveal a major transition in the hardness behavior of nc-Ni at $500 \mathrm{~K}\left(227^{\circ} \mathrm{C}\right)$ as a result of annealing (region III). In addition, according to Figure 6, the hardness of (ED) nc-Ni is almost constant below $350 \mathrm{~K}\left(77^{\circ} \mathrm{C}\right)$ and for short holding annealing times (region I) and slightly increases with increasing annealing temperatures between 350 and $500 \mathrm{~K}$ (77 and $227^{\circ} \mathrm{C}$ ) (region II, hardening), while it decreases with increasing annealing temperatures above $500 \mathrm{~K}$ $\left(227^{\circ} \mathrm{C}\right)$ (region III, softening).

Softening above $500 \mathrm{~K}\left(227^{\circ} \mathrm{C}\right)$ (region III) can be attributed to the occurrence of significant grain growth. For example, the initial grain size of $20 \mathrm{~nm}$ after annealing at $593 \mathrm{~K}\left(320{ }^{\circ} \mathrm{C}\right)$ grew to $240 \mathrm{~nm}$. According to the conventional HP equation, ${ }^{[23,24]}$ an increase in grain size leads to a decrease in hardness.

The origin of the occurrence of hardening in region II $\left(350 \mathrm{~K}\left(77^{\circ} \mathrm{C}\right)<T<500 \mathrm{~K}\left(227^{\circ} \mathrm{C}\right)\right)$ cannot be attributed to the reduction in porosity level, because the electrodeposition route produces a fully dense nc-Ni. ${ }^{[19]}$ Accordingly, other possible explanations need to be sought. In the following paragraph, one possible explanation, which is based on the available information and the results of the present investigation, is offered.

Recent molecular dynamic simulation by Hasnaoui et $a l .^{[36]}$ has suggested that grain boundaries of as-prepared nc materials are often in a nonequilibrium state after processing and that as a result of thermal annealing, the grain boundaries and triple-junction regions approach equilibrium. This process results in strengthening the material (hardening) and in reducing its ductility. The results of the computer simulation ${ }^{[36]}$ are consistent with the experimental data reported by Wang et $a l .^{[8]}$ for fully dense nc-Ni prepared by electrodeposition the grain size of which was approximately $15 \mathrm{~nm}$. In this regard, the occurrence of region I, which exists at $T<350 \mathrm{~K}\left(77^{\circ} \mathrm{C}\right)$ and in which the hardness remains essentially constant, can be attributed to the possibility that in the temperature range 300 to $350 \mathrm{~K}$ $\left(27\right.$ to $77^{\circ} \mathrm{C}$ ), the kinetics are too slow to induce any changes in the nonequilibrium structure resulting from processing.

Based on the present data, the slight hardening in region II $\left(350 \mathrm{~K}\left(77^{\circ} \mathrm{C}\right)<T<500 \mathrm{~K}\left(227^{\circ} \mathrm{C}\right)\right)$ cannot be entirely explained in terms of the attainment of equilibrium in the grain boundaries and triple junction as a result of annealing, because the data indicate the occurrence of abnormal grain growth in this range of temperature. For example, after annealing at $443 \mathrm{~K}$ $\left(170^{\circ} \mathrm{C}\right.$ ) for 25 hours, more than 50 pet of the grains

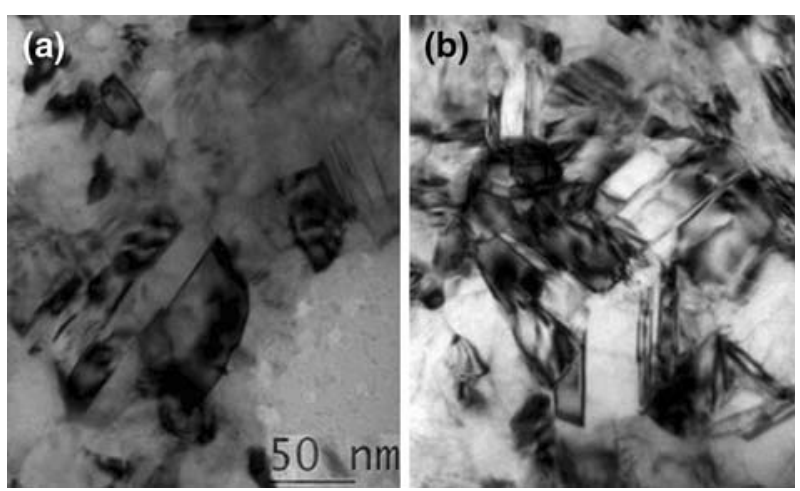

Fig. 9-TEM micrographs of annealing twins in 20-nm nc-Ni annealed at $(a) 443 \mathrm{~K}\left(170^{\circ} \mathrm{C}\right)$ for $25 \mathrm{~h}$ and $(b) 493 \mathrm{~K}\left(220^{\circ} \mathrm{C}\right)$ for $1 \mathrm{~h}$.

exhibited grains sizes $>50 \mathrm{~nm}$. If the effect of these large grains had been considered, softening rather than hardening would have occurred. Accordingly, it is most likely that the annealing process leads to a substructural feature the presence of which becomes responsible for the observation of hardening. This possibility is discussed here.

An examination of the TEM micrographs as exemplified in Figure 9 indicates the presence of twins in the large grains of the samples that were annealed at $443 \mathrm{~K}\left(170^{\circ} \mathrm{C}\right)$ for 25 hours and $493 \mathrm{~K}\left(220^{\circ} \mathrm{C}\right)$ for 1 hour and that showed a bimodal grain size distribution. Twins are also observed at temperatures $>500 \mathrm{~K}$ $\left(227^{\circ} \mathrm{C}\right)$ during normal grain growth, as revealed by the EBSD orientation map in Figure 8, in which twins are identified as "T," although their densities were lower than those noted at temperatures $<500 \mathrm{~K}\left(227^{\circ} \mathrm{C}\right)$. These twins were originated during the annealing process when deformation processes were not involved in the experimental procedure (only heat treatment was carried out). Thus, the induced twins are referred to as annealing twins.

It is documented that twins can serve as a source for strengthening in nc materials. ${ }^{[37,38]}$ Deformation twins are observed in fcc metals and alloys with a low stacking fault energy. However, under severe deformation conditions in nc materials, twins have also been observed in metals with a higher stacking fault energy. The primary effects of the presence of twins are the following: (1) the grains are subdivided into smaller grains (the effective grain size becomes much smaller than that initially characterized by TEM) and (2) twin boundaries, like grain boundaries, can serve as barriers to dislocation motion. In this regard, it was shown that $\mathrm{Cu}$ conventional HP behavior was valid when the twin spacing was replaced by the grain size. ${ }^{[39]}$

In Figure 10, the values of hardness measured following annealing are plotted against the grain size. An examination of the figure indicates that the values of hardness are much higher than those predicted from conventional HP behavior for the measured grain sizes. In order to check whether the difference between experimental measurements and prediction may arise from the effect of the presence of annealing twins in the 


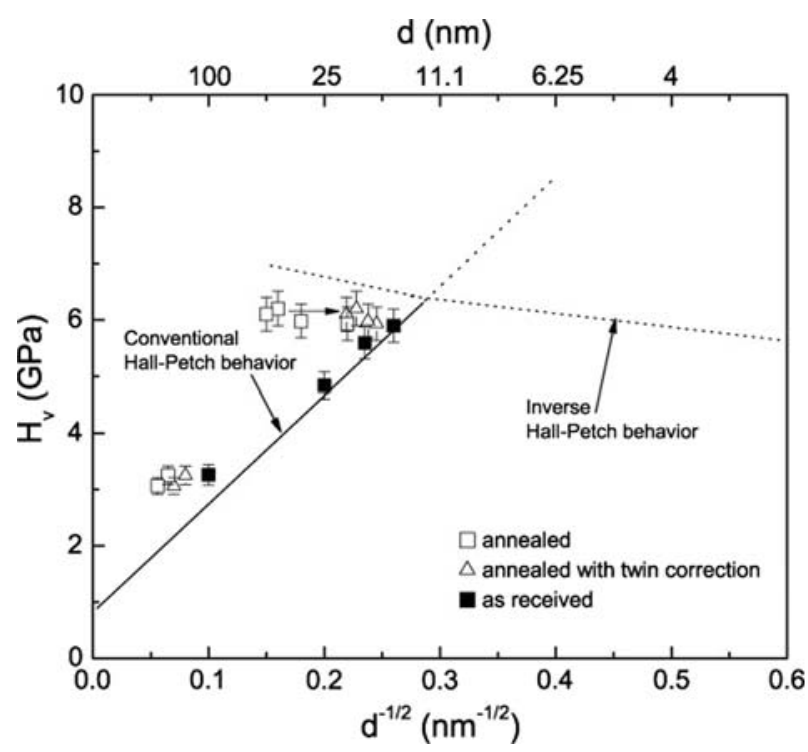

Fig. 10-Hardness of (ED) nc-Ni as a function of the inverse square root of the grain size. Included in the figure is a curve ${ }^{[22]}$ that has two branches representing conventional HP behavior (left side) and inverse HP behavior (right side).

interiors of the grains, a number of representative TEM micrographs were used to estimate the effective grain size. ${ }^{[40]}$ The values of effective grain sizes obtained as a result of the twinning correction (represented by triangles) along with those of the grain sizes prior to making the correction (represented by squares) are shown in Figure 10. It is clear that as a result of incorporating the effect of annealing twins, considerable improvement in the correlation between the experimental values of the hardness and the position of the line representing conventional HP behavior is achieved. Equally important is the finding that the average effective grain sizes in the region of hardening (low annealing temperatures) are slightly less than the initial grain size of $20 \mathrm{~nm}$ (Table III). This finding tends to explain in part the slightly high values measured for hardness at annealing temperatures lower than $500 \mathrm{~K}\left(227^{\circ} \mathrm{C}\right)$, despite the occurrence of some grain growth.

\section{Modulus of Elasticity}

The modulus of elasticity $E$ of as-received (ED) nc-Ni was found to be $165 \pm 10 \mathrm{GPa}$. This value can be compared with values for the modulus estimated from two sources. First, according to the Hill approximation $^{[41]}$ for averaging different grain size orientations, the $E$ for coarse-grained Ni was estimated to be $213 \mathrm{GPa}$. Second, the upper and the lower bounds for $E$ in polycrystalline $\mathrm{Ni}$ can be estimated here using the Voigt's average and the Reuss average, respectively. The Voigt's average for the modulus of elasticity is given by ${ }^{[42]}$

$$
E_{v}=\frac{(F-G+3 H)(F+2 G)}{(2 F+3 G+H)}
$$

where $F=\frac{1}{3}\left(C_{11}+C_{22}+C_{33}\right), G=\frac{1}{3}\left(C_{12}+C_{23}+C_{13}\right)$, and $H=\frac{1}{3}\left(C_{44}+C_{55}+C_{66}\right)$. The Reuss average for Young modulus is given by ${ }^{[41]}$

$$
\left(E_{\mathrm{R}}\right)^{-1}=\frac{1}{5}\left[3 F^{\prime}+2 G^{\prime}+H^{\prime}\right]
$$

where $F^{\prime}=\frac{1}{3}\left(S_{11}+S_{22}+S_{33}\right), G^{\prime}=\frac{1}{3}\left(S_{12}+S_{23}+S_{13}\right)$, and $H^{\prime}=\frac{1}{3}\left(S_{44}+S_{55}+S_{66}\right)$.

Under the condition of cubic symmetry, $C_{11}=$ $C_{22}=C_{33}, C_{12}=C_{23}=C_{13}$, and $C_{44}=C_{55}=C_{66}$ (the same characteristic applies to the elastic compliances $S$ ). Using the elastic compliances for monocrystalline nickel at ambient temperature $\left(S_{11}=0.734 \times\right.$ $10^{-2}, \quad S_{12}=-0.274 \times 10^{-2}, \quad$ and $\quad S_{44}=0.802 \times$ $\left.10^{-2} \mathrm{GPa}^{-1}\right)$ and the elastic stiffness ${ }^{[43,44]}\left(C_{11}=\right.$ $252.8, C_{12}=152.0$, and $\left.C_{44}=123.8 \mathrm{GPa}\right), E_{\mathrm{v}}$ and $E_{\mathrm{R}}$ were calculated as $\sim 240$ and $200 \mathrm{GPa}$, respectively. ${ }^{[4]}$ A comparison between the values of the modulus of elasticity obtained from the aforementioned sources and the value of the modulus of as-received nc-Ni shows clearly that the latter value is lower than the following: (1) the value based on the Hill approximation $^{[41]}$ and (2) the lower bound of $E$ as defined by $E_{\mathrm{R}}$.

According to the XRD profiles (Figure 1), a strong (200) texture was detected in the material. It is quite possible that this texture may be responsible for the reduced value of $165 \mathrm{GPa}$ for the modulus of elasticity of the as-received nc-Ni. Three pieces of information lend support to this possibility. First, Fritz et al. ${ }^{[29]}$ reported an $E$ value of $165 \mathrm{GPa}$ in nc-Ni that exhibited preferred orientation along the (100) planes. Second, as shown in Figure 7, the modulus increases continuously with the increasing annealing temperature, approaching a maximum plateau of approximately $240 \mathrm{GPa}$. This finding parallels in trend XRD profiles for annealed sample of nc-Ni, which show that the strong (200) texture continues to diminish with increasing annealing temperature. Third, the modulus of elasticity depends

Table III. Average Grain Size Values of 20-nm nc-Ni Samples Annealed for 1 and 25 Hours before and after Correcting for the Presence of Annealing Twins

\begin{tabular}{lcr}
\hline & Before Twin Correction $(\mathrm{nm})$ & After Twin Correction (nm) \\
\hline Annealed at 393 K $\left(120^{\circ} \mathrm{C}\right), 1 \mathrm{~h}$ & $20.8 \pm 7.05$ & $16.6 \pm 6.5$ \\
Annealed at 493 K $\left(220^{\circ} \mathrm{C}\right), 1 \mathrm{~h}$ & $38.8 \pm 13.6$ & $19.3 \pm 9.6$ \\
Annealed at 593 K $\left(320^{\circ} \mathrm{C}\right), 1 \mathrm{~h}$ & $240 \pm 73.5$ & $175 \pm 73.1$ \\
Annealed at 693 K $\left(420^{\circ} \mathrm{C}\right), 1 \mathrm{~h}$ & $322.3 \pm 40.7$ & $236.3 \pm 57.1$ \\
Annealed at 393 K $\left(120^{\circ} \mathrm{C}\right), 25 \mathrm{~h}$ & $31.5 \pm 9.57$ & $17.7 \pm 7.68$ \\
Annealed at $443 \mathrm{~K}\left(170^{\circ} \mathrm{C}\right), 25 \mathrm{~h}$ & $46.3 \pm 11.94$ & $20.8 \pm 9.12$ \\
\hline
\end{tabular}


on the orientation of the material. In a cubic material such as $\mathrm{Ni}$, the modulus of elasticity can be determined along any orientation using the following expression: ${ }^{[44]}$

$$
\frac{1}{E}=S_{11}+2 F\left(S_{12}+\frac{S_{44}}{2}-S_{11}\right)
$$

with $F=l x x^{\prime 2} l y x^{\prime 2}+l y x^{\prime 2} l z x^{\prime 2}+l z x^{\prime 2} l x x^{\prime 2}$ where $F$ is an orientation factor, $l x x^{\prime}$ is cosine the angle between $x^{\prime}$ and $x, l y x^{\prime}$ is cosine the angle between $x^{\prime}$ and $y$, and $l z x^{\prime}$ is cosine the angle between $x^{\prime}$ and $z$. Using the elastic compliances for monocrystalline nickel that were given earlier, $E$ values at [100], [220], and [111] were calculated as $\sim 140,232$, and $300 \mathrm{GPa}$, respectively. A comparison between these estimated values of $E$ and the experimental value of $165 \mathrm{GPa}$ (as-received nc-Ni) indicates that the preferred orientation along the (100) planes is most likely responsible for the reduced value of $E$ measured for as-received nc-Ni. Finally, the texture along (200) is lost above $500 \mathrm{~K}\left(227^{\circ} \mathrm{C}\right)$, as indicated by Figure 2(d), and grains become randomly oriented, as shown by EBSD orientation maps given in Figure 8. Under these conditions, $E$ approaches a maximum value of approximately $240 \mathrm{GPa}$ that is essentially equal to the Voigt's average estimated above for polycrystalline $\mathrm{Ni}$.

\section{CONCLUSIONS}

As a result of the annealing of fully dense (ED) nc-Ni samples in the temperature range 323 to $693 \mathrm{~K}$ (50 to $420{ }^{\circ} \mathrm{C}$ ), the following observations can be made.

1. Grain growth in (ED) nc-Ni exhibits the following two types of behavior, depending on the annealing temperature.

a. Below $500 \mathrm{~K}\left(227^{\circ} \mathrm{C}\right)$, anomalous grain growth and bimodal grain size distributions are detected.

b. Above $500 \mathrm{~K}\left(227^{\circ} \mathrm{C}\right)$, there is normal grain growth.

2. The variations in the hardness and modulus of elasticity of (ED) nc-Ni with annealing temperature define the following three regions.

a. Region I at $300 \mathrm{~K}\left(27^{\circ} \mathrm{C}\right)<T<350 \mathrm{~K}\left(77^{\circ} \mathrm{C}\right)$ : in this region, the hardness and modulus of elasticity of the nc-Ni remain essentially constant.

b. Region II at $350 \mathrm{~K}\left(77^{\circ} \mathrm{C}\right)<T<500 \mathrm{~K}\left(227^{\circ} \mathrm{C}\right)$ : in this region, the hardness and modulus of elasticity of nc-Ni increase with increasing grain size and the holding time has no significant effect on the value of the hardness.

c. Region III at $T>500 \mathrm{~K}\left(227^{\circ} \mathrm{C}\right)$ : in this region, the hardness drops and then decreases with increasing grain size. In addition, in this region, the hardness depends on the holding time: the higher the holding time, the lower the hardness. On the other hand, the modulus of elasticity approaches a maximum value of $\sim 240 \mathrm{GPa}$.

3. The increase in the hardness of (ED) nc-Ni in region II as a result of annealing can be attributed in part to the presence of annealing twins and in part to the occurrence of relaxation at the initially nonequilibrium grain boundaries. Both processes can lead to strengthening. The softening noted at $T>500 \mathrm{~K}\left(227^{\circ} \mathrm{C}\right)$ is attributed to the occurrence of significant grain growth.

4. The (ED) nc-Ni exhibits a strong (200) texture. The presence of this texture and its variation with the annealing temperature provides explanations for two observations. First, calculations suggest that the presence of the texture can account for the reduced value of the modulus of elasticity of as-received nc-Ni (165 MPa). Second, the modulus increases almost continuously with increasing annealing temperature, approaching a maximum plateau of approximately $240 \mathrm{GPa}$ that is close to the value of the modulus of elasticity estimated for coarse-grained Ni. This variation in modulus parallels in trend XRD profiles for the annealed sample of nc-Ni, which show that the texture continues to diminish with an increasing annealing temperature and that it fully disappears above $500 \mathrm{~K}\left(227^{\circ} \mathrm{C}\right)$.

\section{ACKNOWLEDGMENTS}

This work was supported by National Science Foundation under Grant No. DMR-0702978. The use of the instrumentation in the Carl Zeiss Center of Excellence at UCI is appreciated. One of the authors (AT) is grateful for the support of the Balsells Fellowship. Thanks are extended to Drs. M. Chauhan of the University of California-Irvine (Irvine, CA) and L. Ajdelsztajn of the University of California-Davis (Davis, CA) for their useful assistance.

\section{OPEN ACCESS}

This article is distributed under the terms of the Creative Commons Attribution Noncommercial License which permits any noncommercial use, distribution, and reproduction in any medium, provided the original author(s) and source are credited.

\section{REFERENCES}

1. M.A. Meyers, A. Mishra, and D.J. Benson: Prog. Mater. Sci., 2006, vol. 51, pp. 427-556.

2. F.A. Mohamed and Y. Li: Mater. Sci. Eng., 2001, vol. A298, pp. 1-15.

3. A.H. Chokshi, A. Rosen, J. Karch, and H. Gleiter: Scripta Metall., 1989, vol. 23, pp. 1679-84.

4. G.W. Nieman, J.R. Weertman, and R.W. Siegel: J. Mater. Res., 1991, vol. 6, pp. 1012-27.

5. J.R. Weertman: Mater. Sci. Eng., 1993, vol. A166, pp. 161-67.

6. R.W. Siegel and G.E. Fougere: Nanostruct. Mater., 1995, vol. 6, pp. 205-16.

7. A.M. El-Sherik, U. Erb, G. Palumbo, and K.T. Aust: Scripta Metall. Mater., 1992, vol. 27, pp. 1185-88.

8. Y.M. Wang, S. Cheng, Q.M. Wei, E. Ma, T.G. Nieh, and A. Hamza: Scripta Mater., 2004, vol. 51, pp. 1023-28. 
9. F. Dalla Torre, H. Van Swygenhoven, and M. Victoria: Acta Mater., 2002, vol. 50, pp. 3957-70.

10. Y. Zhou, U. Erb, K.T. Aust, and G. Palumbo: Scripta Mater., 2003, vol. 48, pp. 825-30.

11. G.E. Fougere, J.R. Weertman, R.W. Siegel, and S. Kim: Scripta Metall. Mater., 1992, vol. 26, pp. 1879-83.

12. W.Y. Chen, S.K. Tien, F.B. Wu, and J.G. Duh: Surf. Coat. Technol., 2004, vol. 182, pp. 85-91.

13. B. Yang and H. Vehoff: Mater. Sci. Eng., 2005, vols. 400-401, pp. $467-70$.

14. G.E. Fougere, J.R. Weertman, and R.W. Siegel: Nanostruct. Mater., 1995, vol. 5, pp. 127-34.

15. P.G. Sanders, J.A. Eastman, and J.R. Weertman: Acta Mater., 1997, vol. 45, pp. 4019-25.

16. R.M. Spriggs: J. Am. Ceram. Soc., 1961, vol. 44, pp. 628-29.

17. M. Chauhan and F.A. Mohamed: Mater. Sci. Eng., 2006, vol. A427, pp. 7-15.

18. F.A. Mohamed and M. Chauhan: Metall. Mater. Trans. A, 2006, vol. 37A, pp. 3555-67.

19. T.R. Haasz, K.T. Aust, G. Palumbo, A.M. El-Sherik, and U. Erb: Scripta Metall. Mater., 1995, vol. 32, pp. 423-26.

20. W.C. Oliver and G.M. Pharr: J. Mater. Res., 1992, vol. 7, pp. 1564-83.

21. K.P. Kulg and L.E. Alexander: X-Ray Diffraction Procedures, John Wiley \& Sons, New York, NY, 1974.

22. F.A. Mohamed: Metall. Mater. Trans. A, 2007, vol. 38A, pp. 340 47.

23. E.O. Hall: Proc. Phys. Soc., 1951, vol. 64, pp. 747-53.

24. N.J. Petch: J. Iron Steel Inst., 1953, vol. 174, pp. 25-28.

25. M. Chauhan and F.A. Mohamed: University of California-Irvine, Irvine, CA, unpublished research, 2007.

26. F. Ebrahimi, G.R. Bourne, M.S. Kelly, and T.E. Matthews: Nanostruct. Mater., 1991, vol. 11, pp. 343-50.
27. F. Dalla Torre, H. Van Swygenhoven, R. Schaublin, P. Spätig, and M. Victoria: Scripta Mater., 2005, vol. 53, pp. 23-27.

28. A.M. El-Sherik, U. Erb, and J. Page: Surf. Coat. Technol., 1996, vol. 88 , pp. 70-78.

29. U. Klement, U. Erb, and K.T. Aust: Nanostruct. Mater., 1995, vol. 6, pp. 581-84.

30. Z. Zhang, F. Zhou, and E.J. Lavernia: Metall. Mater. Trans. A, 2003, vol. 34A, pp. 1349-55.

31. H.G. Jiang, M. Rühle, and E.J. Lavernia: J. Mater. Res., 1999, vol. 14, pp. 549-59.

32. T.H. De Keijser, J.I. Langford, E.J. Mittemeijer, and A.B.P. Vogels: J. Appl. Cryst., 1982, vol. 15, pp. 308-14.

33. M. Chauhan and F.A. Mohamed: J. Mater. Sci., 2007, vol. 42, pp. 1606-14.

34. R. Mitra, T. Ungar, and J.R. Weertman: Trans. Indian Inst. Met., 2005, vol. 58, pp. 1125-32.

35. J. He, J. Ye, E.J. Lavernia, D. Matejcztk, C. Bampton, and J.M. Schoenung: J. Mater. Sci., 2004, vol. 39, pp. 6957-64.

36. A. Hasnaoui, H. Van Swygenhoven, and P.M. Derlet: Acta Mater., 2002, vol. 50, pp. 3927-39.

37. C.J. Youngdahl, J.R. Weertman, R.C. Hugo, and H.H. Kung: Scripta Mater., 2001, vol. 33, pp. 1475-78.

38. L. Lu, Y. Shen, X. Chen, L. Qian, and K. Lu: Science, 2004, vol. 304, pp. 422-26.

39. R.J. Asaro and S. Suresh: Acta Mater., 2005, vol. 53, pp. 3369-82.

40. C.S. Smith and L. Guttman: Trans. AIME, 1953, vol. 197, pp. 81-87.

41. G. Grimvall: Thermophysical Properties of Materials, North Holland/Elsevier, Amsterdam, The Netherlands, 1999.

42. G.A. Alers, J.R. Neighbours, and H. Sato: J. Phys. Chem. Solids, 1960, vol. 13, pp. 40-55.

43. H.B. Huntington: Solid State Phys., 1958, vol. 7, pp. 213-351.

44. M.A. Meyers and K.K. Chawla: Mechanical Behavior of Materials, Prentice Hall, Upper Saddle River, NJ, 1998. 